\title{
Transcultural adaptation and psychometric properties of Family Quality of Life Survey for caregivers of people with neurodegenerative disease: a study of Spanish families who live in the rural Spain-Portugal cross-border
}

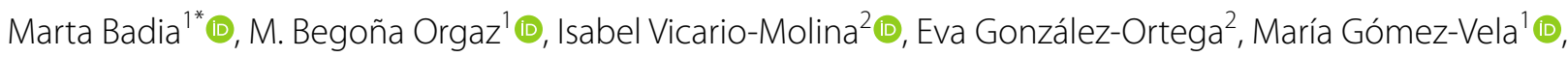
Alba Aza ${ }^{1}$ and M. Antonia Martín-Delgado ${ }^{3}$

\begin{abstract}
Background: Neurodegenerative diseases (NDs) are one of the main causes of disability and dependence that have a great impact both on the quality of life of people with disabilities and their families. A majority of people with NDs receive care and support from the family, but there is no tool in Spain with which to measure whole-family QOL. The aim of this study was the translation, cultural adaptation, and validation of the FQOLS-Dementia into Spanish to assess FQOL among family members of individuals with NDs who live in the Spain-Portugal cross-border area.
\end{abstract}

Method: The Spanish version was translated and adapted following the international guidelines for cross-cultural adaptation tests. A sample of 300 family caregivers was interviewed, applying an adapted version of the Family Quality Survey (FQOLS-Dementia). Confirmatory factor analysis was performed to validate the factor structure, and convergent validity was examined with Pearson's correlation coefficients of the global FQOL with the domains. Internal consistency reliability was determined using Cronbach's alpha.

Results: The domain structure of the FQOLS-ND showed a good fit. In the convergent validity, it was found that the total score and the subscale domain scores were associated with the global FQOL score, except for the Values domain. Internal consistency of nine domain subscales was strong ( $a=0.80$ to 0.91$)$, and excellent for the total FQOL $(a=0.85)$ and the global FQOL $(a=0.87)$.

Conclusion: The FQOLS-ND presented good validity and reliability in caregiver families with individuals with ND, so its application shows its usefulness in detecting areas of improvement and intervention strategies for FQOL in the Spain-Portugal cross-border area.

Keywords: Family quality of life, Neurodegenerative diseases, FQOLS-ND, Cross-cultural adaptation, Psychometric properties

\footnotetext{
*Correspondence: badia@usal.es

${ }^{1}$ Institute on Community Integration (INICO), Faculty of Psychology,

University of Salamanca, Avda. de la Merced, 109-131, 37005 Salamanca, Spain

Full list of author information is available at the end of the article
}

\section{Background}

Neurodegenerative diseases (NDs) are one of the principal causes of disability and dependence worldwide, which have a major impact both on the health and psychological and social well-being of the people who suffer permits use, sharing, adaptation, distribution and reproduction in any medium or format, as long as you give appropriate credit to the original author(s) and the source, provide a link to the Creative Commons licence, and indicate if changes were made. The images or other third party material in this article are included in the article's Creative Commons licence, unless indicated otherwise in a credit line to the material. If material is not included in the article's Creative Commons licence and your intended use is not permitted by statutory regulation or exceeds the permitted use, you will need to obtain permission directly from the copyright holder. To view a copy of this licence, visit http://creativecommons.org/licenses/by/4.0/. The Creative Commons Public Domain Dedication waiver (http://creativeco mmons.org/publicdomain/zero/1.0/) applies to the data made available in this article, unless otherwise stated in a credit line to the data. 
from them and their families [1]. The prevalence of NDs in Spain reaches $2.08 \%$ of the population, representing a total of 988,000 affected people [2]. Twenty-two percent of these people with NDs live in rural areas [2], regions characterized by a strong aging process and depopulation [3]. The prevalence of NDs in the rural cross-border Spain-Portugal population of the province of Salamanca (Castile and Leon, Spain) is 2.51\%, slightly higher than in the Spanish population (2.08\%) [4].

The caregiver family plays a crucial role in supporting the well-being of the person with ND, allowing them to live at home for as long as possible [3, 4]. Therefore, the family is one of the main providers of support services for the person with ND, often producing a high economic and social cost for the family unit [5]. In Spain, families assume most of the expenditure ( $87 \%$ of the total) of the needs of people with ND and dedicate an average of $70 \mathrm{~h}$ per week to caring for their relative [6].

Most of the studies have focused on the primary caregiver, finding burden care symptoms such as stress, anxiety, and depression [5-8]. However, little is known about how the person with ND affects the family as a whole [9-12].

In the 1990s, a paradigm shift took place, with the emergence of the family-centered model and intervention in people with developmental disabilities (DD) in the field of study [13-16]. At present, the Family Quality of Life (FQOL) paradigm has been consolidated and has become a reference for the organization and planning of services and programs for the families of people with DD [17-21].

The FQOL is a multidimensional social construct that reflects the positive values and life experiences of the family $[15,22,23]$. The FQOL is a dynamic sense of wellbeing of the family, collectively and subjectively defined and informed by its members, in which individual and family-level interact. That is, a family perceives quality of life (QOL) when its members' needs are met, they enjoy their life together, and have opportunities to achieve goals that are transcendental for them [15]. More specifically, families experiment QOL when (a) they manage to carry out what they want, (b) they are satisfied with their attainment, and (c) they feel capable of living the life they want [24].

As in the field of study of family caregivers of people with DD, in the study and interventions in the field of NDs, a change in the approach is taking place, overcoming the classic conceptions based on the "model of deficits/stress". In the new model, the "family quality of life model", these families are considered to have coping difficulties, poor physical and social well-being, and feelings of guilt, and the objective of the model is to improve the quality of life of these families $[11,25,26]$. Caring for a person with ND not only leads to burden for the primary caregiver but also has adverse effects on family interactions and changes in family functions [10]. The family-systems approach emphasizes the interaction and interdependence among family members and emphasizes that any change, such as a health problem for one of the members, will have repercussions on all the others [27].

Recently, there has been considerable research on the conceptualization, measurement, and improvement of the quality of life of families, although much of the studies have focused on families of individuals with DD [28, 29]. The International Family Quality of Life Project was initiated in 1997 by researchers from Australia, Canada, and Israel. It examines the quality of life of families who have one or more members with a DD to advance in the approach to the FQOL construct and develop an evaluation tool [13]. Currently, this project involves the collaboration of a team of researchers from several countries around the world. For these experts, the principles that guide the application of the conceptual model of FQOL are: (1) FQOL is a multidimensional construct and influenced by several factors; (2) it comprises the same dimensions for all people; (3) it includes objective and subjective components; and (4) it is best studied using qualitative and quantitative methodology [13]. Five factors were identified as contributing to FQOL in families providing care to people with dementia: (1) family interactions, (2) support of direct care/activities of daily living; (3) emotional/behavioral well-being; (4) physical and cognitive well-being; and (5) disability support/medical care [25].

To assess the degree to which FQOL is enjoyable, meaningful, and supported by resources that are important to all family members, the FQOL project developed the Family Quality of Life Survey (FQOLS-2006) [30-32]. This tool collects quantitative data (on Likert scales) and qualitative data (through open questions) on six measurement dimensions (Importance, Opportunities, Initiative, Stability, Attainment, and Satisfaction) in nine domains of FQOL (Health of the family, Financial well-being, Family relationships, Support from other people, Support from disability-related services, Influence of values, Careers, Leisure and recreation, and Community interaction). The final section of the survey includes items about overall impressions of FQOL [30]. The survey had good reliability and validity for caregivers of people with DD [3133]. Using data from Australia, Canada, and the United States, it was reported that the four indicators (Initiative, Opportunities, Attainment, and Satisfaction), and the nine-domain factor structure of the FQOLS-2006 had an acceptable level of construct validity $\left[\chi^{2}(27)=55.32\right.$, $p<0.00$, CFI $=0.93$, AGFI $=0.94$ RMSEA $=0.06$ ] [31]. Concurrent validity showed moderate correlations 
between five FQOLS-2006 domains and conceptually related domains. Cronbach's alpha internal consistency of the nine domains ranged from poor to good (0.43 to 0.83 ) and, for the two-item global FQOL, it was 0.85 [33].

The FQOLS-2006 was designed to evaluate FQOL in families that have a member with DD, but recently, there is a new version for primary caregivers of people with dementia [34]. Modifications of the original survey included: (a) the adaptation of language to reflect the perspective of a caregiver of a person with dementia; (b) the incorporation in the About your family section of thirteen items and five categories of responses that measured the level of independence in six activities of daily life (i.e., eating, grooming, dressing, etc.) and five practical activities (i.e., housekeeping, shopping, money management, etc.); and (c) the differentiation between practical support and emotional support in the area Support from other people [34]. The internal consistency was high for two item-item global FQOL scale (Cronbach's alpha $=0.85$ ) and for the FQOLS-Dementia domain scales, it ranged from poor to good (Cronbach's alpha range $=0.56-0.85$ ). The domainlevel outcomes of the scales' internal consistency were considered good [9].

This study aimed to: (1) translate and culturally adapt the FQOLS-Dementia into Spanish, to assess the FQOL among family members of individuals with NDs who live in the cross-border area Spain-Portugal; and (2) further examine the specific psychometric properties of reliability and validity.

\section{Method}

\section{Participants and study setting}

Participants were recruited from Regional Health Management (RHM) of Castille and Leon (Spain), between October 2019 and July 2020. Family members of patients with NDs were invited to participate in the study if they met the following inclusion criteria: (1) being a family member of a person with an ND; (2) contributing to the daily care of the person with ND but not necessarily the primary caregiver; (3) being 18 years of age or older; (4) providing their consent; and (5) residing in the cross-border area of Spain-Portugal (Salamanca, Castille Leon). Families whose relative with an ND lived in residential accommodation were excluded.

The sample size $(n=348)$ was calculated through the prevalence of NDs in the cross-border area Spain-Portugal in 2020 ( $N=987$; Dementia: 58.7\%, Parkinson: 37.37\%, Multiple Sclerosis: 3.7\%), using statistic tables [35]. The RHM selected 890 families of patients with ND, and 380 families signed the informed consent to participate. The final sample was composed of 300 participants (Fig. 1).

\section{Instrument: The Family Quality of Life Survey-Dementia}

The FQOLS-Dementia instrument was developed to measure the QOL of families with at least one member with dementia [34]. This survey has several parts. The first one, About your Family, collects descriptive information about the family. The next nine parts ask about specific domains of family life, concretely, Family Health, Financial well-being, Family relationships, Support from others, Support from services, Values, Careers, Leisure and recreation, and Community interaction. Each part contains two sections. Section A addresses the context and general information, and Section B assesses the importance, opportunities, initiative, stability, attainment, and satisfaction with the specific domain of family life. While attainment and satisfaction are considered outcome dimensions, importance, opportunities, initiative, and stability are explanatory dimensions [13]. All Section B items are rated on a 5-point Likert scale ranging from 1 (Hardly important at all) to 5 (Very important). The last part of the instrument asks about general impressions related to FQOL. The reliability of the attainment and satisfaction dimensions of the FQOLS-Dementia ranged from moderate (0.56) to good (0.85) [9].

\section{Translation and adaptation process}

The process of translation, adaptation, and validation of the FQOLS-Dementia [9] to the Spanish context for families caring for people with an ND (FQOLS-ND) was carried out following the guidelines and recommendations for test adaptation proposed by the International Testing Commission (ITC) [36, 37].

The translation and adaptation process was performed in 6 phases: (1) translation of each item to Spanish by two different translators with knowledge and experience in the field of FQOL. For each item, the translators indicated the degree of difficulty and the level of equivalence of the translation on a scale ranging from 1 to 10 ; (2) synthesis of the translations by agreement of the two translators, resulting in the first Spanish version of the original instrument; (3) selection of two focus groups, one with four families of an individual with an ND and another group with eight professionals of social services to analyze the cultural acceptability, make suggestions, and ensure the suitability of the items; (5) concordance and synthesis was performed by a committee of experts made up of four researchers of NEUROQUALYFAM team (cross-border Spain-Portugal cooperation project with the support of the European Union-POCTEP) to achieve the semantic, idiomatic, and conceptual equivalence of the survey; (6) the backward translation of the adapted instrument was carried out by a $\mathrm{PhD}$ in Psychology, whose maternal language is English and who is bilingual 
People with neurodegenerative disease with whom initial contact was made $(\mathrm{RMH})$ $\mathrm{n}=890$

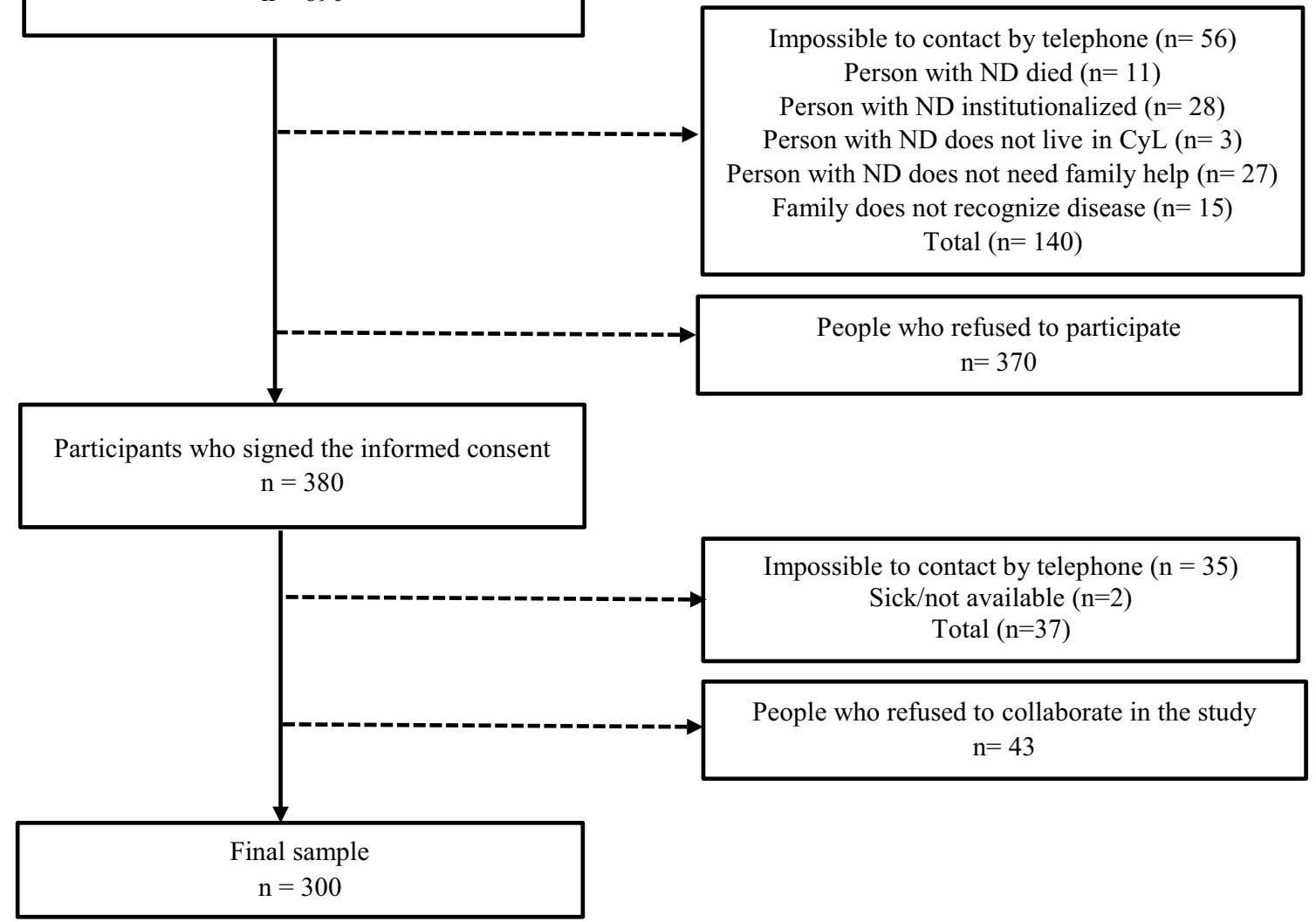

Fig. 1 Sample recruitment process

in Spanish to compare the differences or discrepancies with the original version, thereby obtaining the definite version of the FQOLS-ND.

\section{Data collection and procedure}

The identification of potential participants was carried out by the Regional Management of Health (RMH) of Castille and Leon, which sent certified letters to the selected families with information about the study and the request for them to consent to participate, and to the coordinator of the Primary Care Management of Salamanca province to present the research to the families of patients with ND.

As a consequence of the COVID-19 pandemic, data collection was redesigned because the length of the tool made it difficult to administer. For this reason, only the attainment (the degree to which the family can obtain the things that it wants) and satisfaction (the overall perception of important aspects of family life) dimensions were evaluated. The decision to use these two dimensions was based on the following three considerations: (1) from a psychometric perspective, these dimensions obtained excellent internal consistency (Cronbach's alpha $=0.85$ ) in the validation study of the FQOLS-2006 [31]; (2) from a conceptual perspective, attainment and satisfaction are considered as outcome indicators of FQOL [31]; and (3) when validating the FQOLS-Dementia, only attainment and satisfaction were examined, obtaining Cronbach's alpha coefficients comparable to the original FQOLS2006 [9].

To respect the social distancing restrictions, the questionnaires were administered via telephone by trained and experienced interviewers. Verbal informed consent was obtained after informing the participants about the aim of the study and their right to drop out at any time. Completing the survey took approximately $30 \mathrm{~min}$.

\section{Statistical analysis}

Data were analyzed using SPSS 26.0. First, descriptive statistics of the participants' characteristics were calculated. The feasibility of the survey was determined by the response rate, the time spent to complete the 
questionnaire, the percentage of missing values per item, the distribution of scores, and the frequency of the maximum and minimum values registered.

A descriptive analysis of the items was conducted. Distribution of scores for each item, proportion of missing data, the proportion of "does not apply" responses, and floor and ceiling effects were examined. Floor and ceiling effects were considered to occur when more than $15 \%$ of the respondents endorsed the lowest (1) or highest (5) scores, respectively [38].

\section{Data computation}

Domain subscale total scores were computed as the mean of each domain's two-dimensional ratings: attainment and satisfaction. In the case of the Others domain, the mean of the two dimensions, Emotional and Practical Support, was calculated. This version of the survey generates two types of FQOL scores: (a) the total score, computed by aggregating the 20 items of Section B (i.e., two dimensions of each of the eight domains, and four items from the Others domain); and (b) the global score, computed from the mean of the two items related to the overall FQOL.

\section{Differences between domains and between dimensions}

A descriptive analysis of the domains and dimensions was conducted. A two-factor (domains and dimensions) repeated-measures ANOVA was used, and post hoc comparisons were used to compare the domains and analyze the interactions. The significance level was set at 0.05 . Concerning the interpretation of the effect size $\left(\eta_{\mathrm{p}}{ }^{2}\right)$, we used guidelines proposed by Cohen $(0.01=$ small effect, $0.06=$ moderate effect, $0.14=$ large effect) [39] .

\section{Construct validity}

We determined whether FQOL is a latent variable that can be measured with the nine domains as indicators [13, 31], using Confirmatory Factor Analysis (CFA), with the statistical package AMOS v.18. Maximum Likelihood (ML) techniques were used to estimate model parameters, similar to analyses undertaken by other authors [31, 40], and the model's goodness-of-fit and the significance of the model's parameter estimates were calculated.

Model fit was evaluated using a chi-square test, the Root Mean Squared Error of Approximation (RMSEA $<0.06)$ and the Comparative Fit Index $(\mathrm{CFI}>0.95)$ [41]. Standardized factor loadings $(\lambda)$, squared multiple correlations (SMC), and modification indices were examined to determine whether the indicators contributed significantly to the model. Indicators with low factor loadings $(\lambda<0.50)$ were considered to make a low contribution to the model.

\section{Convergent validity}

Pearson's correlation coefficient values of the domains scores and the total score with the Global FQOLS-ND score were evaluated to examine convergence. Correlation coefficients of about 0.10 were considered to be small, 0.30 medium, and 0.50 large [39].

\section{Reliability assessment}

To evaluate internal consistency, Cronbach's alpha coefficient was calculated for the nine domains. An alpha value between 0.70 and 0.95 was considered satisfactory [42].

\section{Results}

\section{Translation and cultural adaptation}

The survey included some minor modifications. First, a change of term (dementia is replaced by neurodegenerative disease) and modifications related to the wording of the questions to reflect the perspective of families caring for people with ND. Second, this work is part of the NEUROQUALYFAM project, which studies QOL among families with a member who has an ND in the SpainPortugal cross-border area. For this purpose, we removed the open question items due to the difficulty to code them, whereas the shorter extension of the instrument facilitated its application. Third, in the part About Your Family, one item was added to assess the person's officially recognized degree of dependency to carry out basic daily life activities. Fourth, in Section A, minor adjustments were made. For example, in Item 1 of the Services dimension, the different response options to the available support resources for the person with ND were adapted to the Spanish context. Lastly, in Section B, all 60 items of the FQOLS-ND are the same as in the original version. The only change was to replace the term dementia with neurodegenerative disease.

The final version of the FQOLS-ND contains the following parts. The first part, About your family, includes 12 questions about the family and the person with ND. The questions range from general socio-demographic issues to more specific ones, such as the supports needed by the relative with ND or the degree of independence in different daily life activities. The second part contains the same nine domains of the FQOL of the original survey: Family health, Financial well-being, Family relationships, Support from others, Support from services, influence of Values, Careers, Leisure and recreation, and Community interaction. Each of these nine parts has 2 sections: Section A is composed of 33 quantitative items about specific issues within each of the nine core domains of the FQOL. Section B, in each of the nine life domains, six dimensions (or indicators) are used to examine how the family perceives its FQOL. 
These dimensions include importance, opportunities, initiative, stability, attainment, and satisfaction. This section consists of 60 items and collects quantitative data of each of the nine life domains on a 5-point Likert scale, with higher scores indicating higher levels of the specific domain. The final section Overall Family Quality of Life consists of two closed-ended questions about global impressions of the FQOL (Additional file 1).

Table 1 Family caregiver characteristics $(n=300)$

\begin{tabular}{|c|c|c|}
\hline Variable & $\mathrm{n}$ & $\%$ \\
\hline \multicolumn{3}{|l|}{ Age $(M=62.48, D T=13.34$, Range $=25-88)$} \\
\hline Up to 65 years & 178 & 59.3 \\
\hline More than 65 years & 122 & 40.7 \\
\hline \multicolumn{3}{|l|}{ Gender } \\
\hline Male & 90 & 30.0 \\
\hline Female & 210 & 70.0 \\
\hline \multicolumn{3}{|l|}{ Educational level } \\
\hline No school certificate & 21 & 7.0 \\
\hline Elementary school & 150 & 50.0 \\
\hline High school & 68 & 22.8 \\
\hline University & 59 & 19.8 \\
\hline \multicolumn{3}{|l|}{ Employment status } \\
\hline Working (employees + self-employed) & 106 & 35.3 \\
\hline Not working (retired + unemployed + others) & 194 & 64.7 \\
\hline \multicolumn{3}{|l|}{ Income (EUR per month) } \\
\hline Up to 500 & 95 & 31.9 \\
\hline $500-1000$ & 102 & 34.2 \\
\hline $1000-1500$ & 69 & 23.1 \\
\hline More than 1500 & 32 & 10.7 \\
\hline \multicolumn{3}{|l|}{ Marital status } \\
\hline Married or with partner & 239 & 79.7 \\
\hline Others (divorced or separed. widowed. single) & 61 & 20.3 \\
\hline \multicolumn{3}{|l|}{ Place of residence - number of in habitants } \\
\hline More than 10.000 & 61 & 20.3 \\
\hline $500-10.000$ & 107 & 35.7 \\
\hline Up to 500 & 132 & 44.0 \\
\hline \multicolumn{3}{|l|}{ Relationship with person with dementia } \\
\hline Spouse or partner & 117 & 40.9 \\
\hline Son/Daughter & 148 & 51.7 \\
\hline Others & 21 & 7.3 \\
\hline \multicolumn{3}{|l|}{ Primary caregiver } \\
\hline Yes & 280 & 93.3 \\
\hline No & 20 & 6.7 \\
\hline \multicolumn{3}{|l|}{ Living condition } \\
\hline Living with patient & 225 & 75.0 \\
\hline Not living with patient & 75 & 25.0 \\
\hline
\end{tabular}

\section{Descriptive characteristics of the study sample}

Three hundred participants completed the study. Their characteristics are shown in Table 1 . The mean age is 62.4 years $(S D=13.34$, range $=25-88$ years $)$, with almost $60 \%$ aged 65 or above. The majority are females $(70 \%)$, married/living with a partner (79.7\%), unemployed (64.7\%), with low income - up to 1000 EUR per month(66.1\%), and have elementary or high school qualifications $(72.8 \%)$. The vast majority are either the spouse/ partner $(40.9 \%)$ or son/daughter $(51.7 \%)$ of the carerecipient, and are the primary caregiver (93.3\%), with three out of four living in the same household as the carerecipient. Most of them live in rural areas of up to 500 $(44 \%)$ or $500-10,000$ people (35.7\%).

Concerning the characteristics of care-recipients (Table 2), their mean age is 79.3 years $(S D=11.7$, range $=20-98$ ), and most are females $(60 \%)$. All of them suffer from dementia (54.3\%), Parkinson's disease (26.7\%), or multiple sclerosis $(6.7 \%)$ with some degree of dependence [43] (67.3\%) - generally high (46.2\%) or

Table 2 Care-recipient characteristics $(n=300)$

\begin{tabular}{|c|c|c|}
\hline Variable & $\mathbf{n}$ & $\%$ \\
\hline \multicolumn{3}{|l|}{ Age $(\mathrm{M}=79.3, \mathrm{DT}=11.7$, Range $=20-98)$} \\
\hline \multicolumn{3}{|l|}{ Gender } \\
\hline Male & 120 & 40.0 \\
\hline Female & 180 & 60.0 \\
\hline \multicolumn{3}{|l|}{ Diagnosis } \\
\hline Dementia & 163 & 54.3 \\
\hline Parkinson Disease & 80 & 26.7 \\
\hline Multiple Sclerosis & 20 & 6.7 \\
\hline Others (unknown by family; several NDs) & 37 & 12.3 \\
\hline \multicolumn{3}{|l|}{ Dependence } \\
\hline Yes & 202 & 67.3 \\
\hline No & 98 & 32.7 \\
\hline \multicolumn{3}{|l|}{ Grade of dependence } \\
\hline Grade 1 & 46 & 23.1 \\
\hline Grade 2 & 61 & 30.7 \\
\hline Grade 3 & 92 & 46.2 \\
\hline \multicolumn{3}{|l|}{ Supports needed } \\
\hline None & 27 & 9.0 \\
\hline Very few & 32 & 10.7 \\
\hline Some & 75 & 25.0 \\
\hline Quite a lot & 56 & 18.7 \\
\hline A lot & 110 & 36.7 \\
\hline \multicolumn{3}{|l|}{ Communication skills } \\
\hline Poor communication & 76 & 25.3 \\
\hline Only basic needs & 26 & 8.7 \\
\hline Needs, desires, ideas & 42 & 14.0 \\
\hline Coherent on some topic & 66 & 22.0 \\
\hline Cooherent on many topics & 90 & 30.0 \\
\hline
\end{tabular}


moderate (30.7\%). Concerning support, 91\% have support needs, and in $55.4 \%$, these needs are high. Of these people, $48 \%$ cannot maintain a coherent conversation.

\section{Descriptive characteristics of the FQOLS-ND}

The percentage of missing data for each item was $0 \%$. The minimum and maximum scores in every item were 1 and 5 (only in the dimensions of attainment and satisfaction of the domain Family Health had a minimum score of 2).

A ceiling effect in the domains of Family (53.0\%) and Careers (19.0\%) was observed for the attainment dimension. A ceiling effect was found for the satisfaction dimension in the domains of Family (50.7\%), Others (18.7\%), and Careers (20.0\%).

Skewness ranged from -1.13 to -0.17 and from -1.40 to -0.23 for attainment and satisfaction, respectively. Kurtosis ranged from -0.13 to 1.38 (attainment) and from -0.61 to 2.56 (satisfaction).

The total FQOLS-ND scores were virtually symmetrical $(-0.45$ and -0.85 , for attainment and satisfaction, respectively), and slightly leptokurtic (1.39 and 1.38, for attainment and satisfaction, respectively) (Table 3 ).

\section{Differences between domains and between dimensions}

The means in attainment and satisfaction in each of the nine domains are shown in Table 3. Attainment and satisfaction mean ratings were similar across the nine domains.
The ANOVA revealed significant differences between the domains, $F(8,2392)=96.77, p<0.001, \eta_{\mathrm{P}}{ }^{2}=0.25$. The domains that participants perceived as significantly higher $(p<0.001)$ were Family $(M=4.38, S D=0.71)$ and Careers $(M=3.97, S D=0.69)$, whereas the domains perceived as significantly lower $(p<0.001)$ were Services $(M=2.97, S D=0.99)$ and Leisure $(M=3.34, S D=0.92)$.

When comparing the domains separately in the dimensions of attainment and satisfaction, results revealed significant differences between scores for the domains in attainment, $F(8,2392)=108.45, p<0.001$, $\eta_{\mathrm{P}}{ }^{2}=0.27$, and satisfaction, $F(8,2392)=64.98$, $p<0.001, \eta_{\mathrm{P}}^{2}=0.18$. The domains that participants perceived as significantly higher $(p<0.001)$ in attainment were Family $(M=4.41, S D=0.72)$ and Careers $(M=3.96, S D=0.71)$, whereas the domains perceived as significantly lower $(p<0.001)$ in attainment were Services $(M=2.83, S D=1.02)$ and Others $(M=3.19$, $S D=1.14)$. In terms of satisfaction with the domains, the participants reported significantly higher satisfaction $(p<0.001)$ in the domains of Family $(M=4.35$, $S D=0.80)$ and Careers $(M=3.98, S D=0.75)$, whereas Services $(M=3.11, S D=1.11)$ and Leisure $(M=3.43$, $S D=0.95)$ were perceived as significantly less satisfactory $(p<0.001)$.

Results indicated a statistically significant difference between the dimensions, $F(1,299)=118.96, p<0.001$, $\eta_{\mathrm{P}}{ }^{2}=0.29$. The mean level of satisfaction experienced

Table 3 Descriptive characteristics of the FQOLS-ND

\begin{tabular}{|c|c|c|c|c|c|c|c|c|c|c|}
\hline \multirow[t]{2}{*}{ Domains } & \multicolumn{5}{|c|}{ Attainment } & \multicolumn{5}{|c|}{ Satisfaction } \\
\hline & $M(S D)$ & Skewness & Kurtosis & \% Floor & $\%$ Ceiling & $M(S D)$ & Skewness & Kurtosis & \% Floor & $\%$ Ceiling \\
\hline Health & $\begin{array}{l}3.64 \\
(0.69)\end{array}$ & -0.52 & 0.20 & $0.0 \%$ & $6.0 \%$ & $\begin{array}{l}3.66 \\
(0.84)\end{array}$ & -0.72 & 0.42 & $1.0 \%$ & $11.0 \%$ \\
\hline Finances & $\begin{array}{l}3.53 \\
(0.64)\end{array}$ & -0.86 & 0.93 & $0.7 \%$ & $1.3 \%$ & $\begin{array}{l}3.58 \\
(0.69)\end{array}$ & -1.19 & 1.46 & $1.0 \%$ & $2.0 \%$ \\
\hline Family & $\begin{array}{l}4.41 \\
(0.72)\end{array}$ & -1.13 & 1.38 & $0.3 \%$ & $53.0 \%$ & $\begin{array}{l}4.35 \\
(0.80)\end{array}$ & -1.40 & 2.00 & $0.7 \%$ & $50.7 \%$ \\
\hline Others & $\begin{array}{l}3.19 \\
(1.14)\end{array}$ & -0.53 & -0.50 & $12.3 \%$ & $8.3 \%$ & $\begin{array}{l}3.76 \\
(0.87)\end{array}$ & -0.44 & 0.03 & $1.0 \%$ & $18.7 \%$ \\
\hline Services & $\begin{array}{l}2.83 \\
(1.02)\end{array}$ & -0.29 & -0.61 & $13.7 \%$ & $2.3 \%$ & $\begin{array}{l}3.11 \\
(1.11)\end{array}$ & -0.56 & -0.61 & $12.7 \%$ & $5.0 \%$ \\
\hline Values & $\begin{array}{l}3.49 \\
(0.86)\end{array}$ & -0.17 & 0.53 & $2.7 \%$ & $13.0 \%$ & $\begin{array}{l}3.64 \\
(0.82)\end{array}$ & -0.23 & 0.46 & $1.7 \%$ & $15.0 \%$ \\
\hline Careers & $\begin{array}{l}3.96 \\
(0.71)\end{array}$ & -0.71 & 1.30 & $0.3 \%$ & $19.0 \%$ & $\begin{array}{l}3.98 \\
(0.75)\end{array}$ & -1.12 & 2.56 & $1.0 \%$ & $20.0 \%$ \\
\hline Leisure & $\begin{array}{l}3.25 \\
(0.98)\end{array}$ & -0.66 & -0.13 & $6.7 \%$ & $4.3 \%$ & $\begin{array}{l}3.43 \\
(0.95)\end{array}$ & -0.92 & 0.42 & $5.3 \%$ & $6.0 \%$ \\
\hline Community & $\begin{array}{l}3.74 \\
(0.80)\end{array}$ & -0.93 & 1.29 & $1.3 \%$ & $11.7 \%$ & $\begin{array}{l}3.83 \\
(0.71)\end{array}$ & -0.89 & 1.80 & $0.7 \%$ & $11.7 \%$ \\
\hline Total scores & $\begin{array}{l}3.52 \\
(0.49)\end{array}$ & -0.45 & 1.39 & & & $\begin{array}{l}3.71 \\
(0.49)\end{array}$ & -0.85 & 1.38 & & \\
\hline
\end{tabular}

Health, Health of family; Finances, Financial wellbeing; Family, Family relationships; Others, Support from other people; Services, Support from disability-related services; Values, Influence of values; Careers, Careers and preparing for careers; Leisure, Leisure and recreation; Community, Community interaction 
$(M=3.71, S D=0.49)$ was significantly higher than mean level of attainment $(M=3.52, S D=0.49)$.

The interaction Domains $\mathrm{x}$ Dimensions was significant, $F(8,2392)=32.69, p<0.001, \eta_{\mathrm{P}}{ }^{2}=0.10$, and the a posteriori tests revealed that the mean level of satisfaction was higher than the mean ratings of attainment in eight of the nine domains, although these differences were only statistically significant in six domains: Finances $(p=0.03)$, Others $(p<0.001)$, Services $(p<0.001)$, Values $(p<0.001)$, Leisure $(p<0.001)$, and Community $(p=0.001)$. The participants reported a higher level of attainment only in the Family domain $(p=0.04)$.

Large effect sizes were found in the domain and dimension factors. However, the effect size of the interaction was medium. A large effect size was also obtained when analyzing the differences between domains separately in the dimensions of attainment and satisfaction.

\section{Construct validity of FQOLS-ND Factor structure}

Results showed that the hypothesized model, consisting of nine indicators (the nine domain subscales) and one latent factor presented a moderate fit, $X^{2}(27)=99.21$, $p<0.001, \mathrm{CFI}=0.84$, $\mathrm{RMSEA}=0.10$.

These results reflect the cultural values of the society in our study, in which the families and close relatives of the person with an ND are characterized by commitment, solidarity, and the family obligation to provide care to the dependent relative [44]. The results also show that the very high economic costs of dementia in Spain are borne by the family, and highlight the impossibility or difficulties to access social-health resources because they are either insufficient or economically inaccessible [44]. For this purpose, an inter-correlation between indicators was proposed, which means that these indicators are related to each other because they all share the quality of representing FQOL. More specifically, correlations were proposed between Others and Values, Family and Values, and Health and Finances.

The inclusion of the error covariance between the domains of Health and Finances, Values, and Family, and of Values and Others improved model fit, $\chi^{2}(24)=31.48$, $p=0.14, \mathrm{CFI}=0.984$, $\mathrm{RMSEA}=0.032$.

All the indicators were statistically significant $(p<0.001)$, as shown in Fig. 2, Leisure $(\lambda=0.78)$ and Community $(\lambda=0.70)$ had the highest factor loadings, whereas Values $(\lambda=0.31)$ Family $(\lambda=0.36)$, and Careers $(\lambda=0.38)$ had the lowest factor loadings. Leisure (61\%) and Community (49\%) also showed the highest contribution to the variance of the latent factor of the FQOL, whereas the contribution of the remaining domains was lower than 30\%: Services and Financial (20\%), Health and
Others (17\%), Careers (14\%), Family (13\%) and Values (9\%).

\section{Correlations between the domain subscales}

Correlations between the domain subscales ranged from weak ( $r=0.06, p>0.05$, the correlation between Finances and Values, which did not reach statistical significance) to strong ( $r=0.55, p<0.001$, the correlation between Leisure and Community). See Table 4.

\section{Convergent validity}

Total and subscale (domain) scores were significantly correlated $(p<0.001)$ with the Global FQOL score, except for the Values domain. The correlation coefficient for the total and Global FQOL scores was large $(r=0.55)$. The magnitude of the correlation coefficients of the Global FQOL score and the domains, in descending order, were: large for Leisure $(r=0.51)$; medium for Community $(r=0.43)$, Health $(r=0.42)$, Finances $(r=0.39)$, and Careers $(r=0.31)$; and small for Services $(r=0.26)$, Family $(r=0.25)$, and Others $(r=0.21)$ (Table 4$)$.

\section{Reliability}

As shown in Table 4, the internal consistency of the nine domain subscales, containing two items each, was satisfactory, with alphas ranging from Cronbach $\alpha=0.80$ to 0.91 . Moreover, internal consistency was excellent for the total 18-item FQOL scale (Cronbach's alpha $=0.85$ ) and for the Global FQOL scale, containing two items related to the overall FQOL (Cronbach's alpha $=0.87$ ).

\section{Discussion}

The purpose of this study was to translate, culturally adapt, and validate the FQOLS-Dementia that takes into account the characteristics of the target population, families who care for people with NDs in the cross-border area Spain-Portugal.

The analysis of the scores found almost no ceiling or floor effects in the dimensions within each of the domains, with $15 \%$ considered the maximum acceptable. However, on the one hand, the Family and Careers domains had a ceiling effect in the attainment dimension. This indicates that the family perceives that can it achieve quality relationships among the different family members. That is, the family achieves a high degree of support, respect, and mutual trust, and can reach agreements and decisions, and remains together. This result is similar to that obtained by previous studies that consider that affection and solidarity among family members in the care of dependents are aspects of great value [11, 19]. Moreover, unlike in previous studies, caring functions performed by the families do not imply giving up the academic and professional career of any of its members [2, 


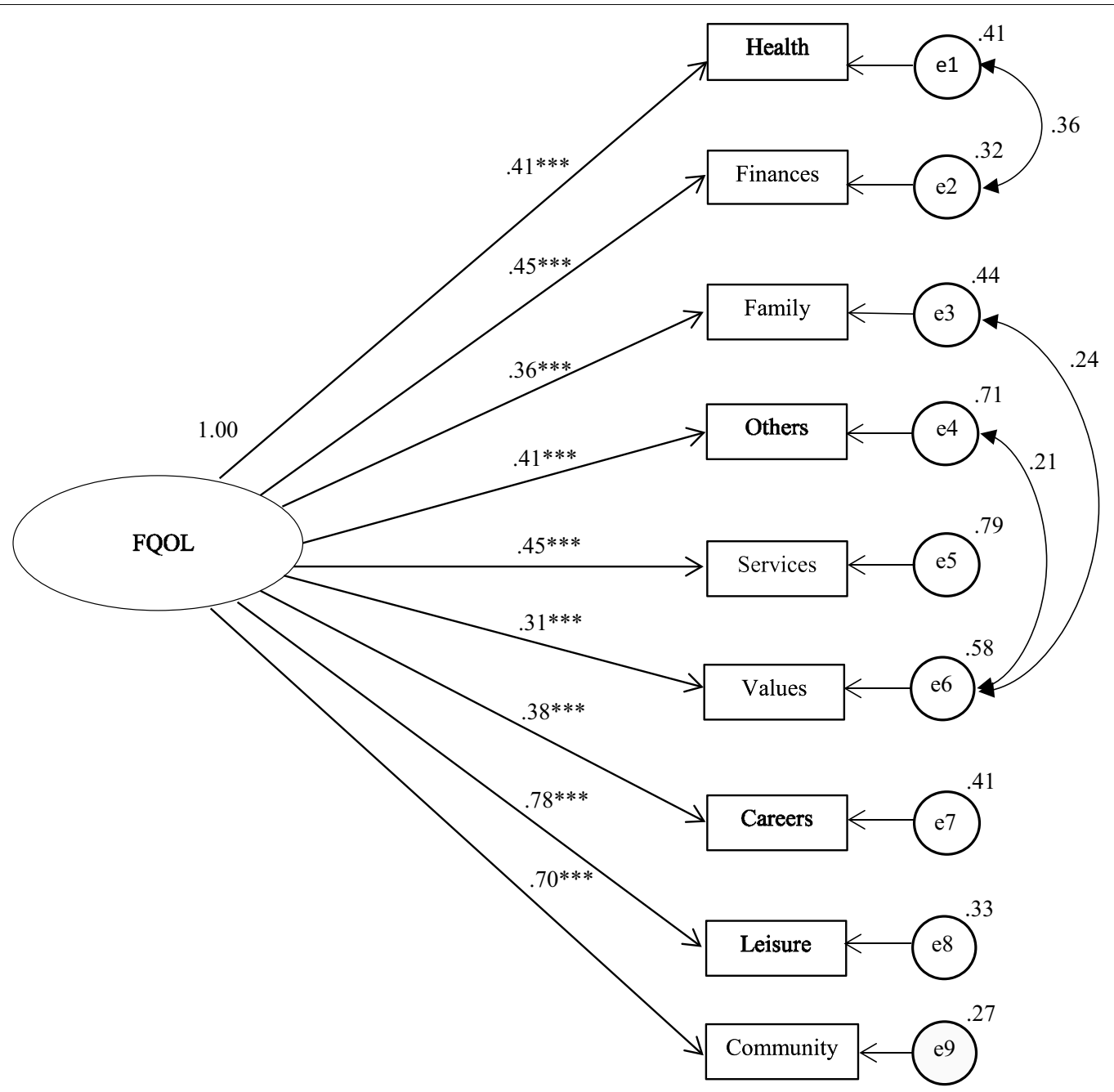

Fig. 2 Domain structure of total FQOLS-ND

Table 4 Correlation matrix and Cronbachs's a of FQOL domains

\begin{tabular}{|c|c|c|c|c|c|c|c|c|c|c|}
\hline & 1 & 2 & 3 & 4 & 5 & 6 & 7 & 8 & 9 & 10 \\
\hline 1. Health & .82 & & & & & & & & & \\
\hline 2. Finances & $.48^{* * *}$ & .89 & & & & & & & & \\
\hline 3. Family & $.23^{* * *}$ & $.18^{* *}$ & .85 & & & & & & & \\
\hline 4. Others & $.12^{*}$ & $.15^{* *}$ & $.16^{* *}$ & .80 & & & & & & \\
\hline 5. Services & $.14^{*}$ & $.26^{* * *}$ & $.12^{*}$ & $.23^{* * *}$ &, 85 & & & & & \\
\hline 6. Values & $.13^{*}$ & .06 & $.33^{* * *}$ & $.31^{* * *}$ & $.13^{*}$ & .90 & & & & \\
\hline 7. Careers & $.20 * * *$ & $.14^{*}$ & $.23^{* * *}$ & $.20 * * *$ & .08 & $.24^{* * *}$ & .88 & & & \\
\hline 8. Leisure & $.35^{* * *}$ & $.36^{* * *}$ & $.26^{* * *}$ & $.27 * * *$ & $.36^{* * *}$ & $.23^{* * *}$ & $.29 * * *$ & .90 & & \\
\hline 9. Community & $.26^{* * *}$ & $.29^{* * *}$ & $.24^{* * *}$ & $.33^{* * *}$ & $.31^{* *}$ & $.21^{* * *}$ & $.23^{* * *}$ & $.55^{* * *}$ & .91 & \\
\hline 10. Global FQOL & $.42^{* * *}$ & $.39 * * *$ & $.25^{* * *}$ & $.21 * * *$ & $.26^{* * *}$ & .11 & $.31 * * *$ & $.51^{* * *}$ & $.43^{* * *}$ & .87 \\
\hline Mean (SD) & $\begin{array}{l}3.65 \\
(0.71)\end{array}$ & $\begin{array}{l}3.56 \\
(0.63)\end{array}$ & $\begin{array}{l}4.38 \\
(0.71)\end{array}$ & $\begin{array}{l}3.48 \\
(0.93)\end{array}$ & $\begin{array}{l}2.97 \\
(0.99)\end{array}$ & $\begin{array}{l}3.57 \\
(0.80)\end{array}$ & $\begin{array}{l}3.97 \\
(0.69)\end{array}$ & $\begin{array}{l}3.34 \\
(0.92)\end{array}$ & $\begin{array}{l}3.79 \\
(0.71)\end{array}$ & $\begin{array}{l}3.67 \\
(0.68)\end{array}$ \\
\hline
\end{tabular}

Cronbach's a of the FQOL domain subscales are presented on the diagonal

${ }^{*} p<.05 ;{ }^{* *} p<.01 ; p<.001$ 
45]. On the other hand, the satisfaction dimension had a ceiling effect in the Family, Others, and Careers domains, which reflects the family's high perception of family cohesion, support from the close environment, and opportunities for vocational training and professional qualification. These results are similar to those reported by other authors who point out that the family system is a platform of essential resources to deal with the caring tasks of a family member with dementia, and family caregivers who have a greater social support network reported a better QOL $[44,46]$.

Likewise, the present study examined two outcome measures for each of the nine family life domains of the FQOLS-ND. The attainment and satisfaction means were similar in all nine domains, albeit the Family and Careers domains were rated higher, and the Services and Leisure domains were rated lower. These results have been partially confirmed by previous studies that indicate, on the one hand, the positive effect of quality family relationships and, on the other hand, the low effect that caring for the person with an ND has on the family's training and work activities. They also show the difficulties that the family has to access adequate professional services and enjoy leisure activities $[9,18]$. Also, the results have shown that the satisfaction scores were higher than the scores in attainment, and they were significant in Finances, Others, Services, Values, Leisure, and Community. As is well known, satisfaction scores are often over-estimated because family caregivers tend to report moderately positive levels of well-being, except in rare cases where they feel overwhelmed to the point of not being able to cope with daily challenges [47]. Finally, a noteworthy result was that families reported a higher level of attainment than satisfaction in the Family domain. This may indicate that, despite having achieved good relationships among family members and high levels of co-responsibility in decision-making and problemsolving concerning their caring functions, this was at the cost of a reduction in well-being. In short, the caring family, beyond direct physical care (e.g., administering medication, assisting in daily grooming, preparing meals, etc.), must organize and distribute care responsibilities (e.g., managing health services, care planning, accompaniment to doctors, etc.), which can have negative consequences on family satisfaction $[44,45]$.

The CFA provides empirical support for the construct validity of the $F Q O L S-N D$ for the population of caring families in the cross-border Spain-Portugal area. The CFA allowed us to establish the validity of this scale and supports the FQOL construct proposed by the authors of the original version of the instrument [31]. The CFA produced fit indices clearly suitable for the ninedomain model, better than those obtained by previous studies $[31,40]$. We also found a high contribution of the Leisure and Community domains to FQOL, a similar result to that obtained by a previous study on the psychometric properties of the FQOLS-2006 [40]. That is, the family's opportunities to participate and enjoy leisure activities and free time, as well as their involvement in social life, are factors that lead to better results of FQOL, results that are confirmed by previous scientific literature [46, 48-52]. In short, these results allow us to conclude that the structure of a latent factor, FQOL, represented by the nine domains, is replicated.

In this study, we present the domain structure of the total FQOL as a latent variable that can be measured using nine indicators for each domain [40]. We agree with the authors of the scale that the value of this scale is that it gathers information about a large number of domains or areas of the family in which the family's needs and support resources can be detected, although some domains are less closely related to the other domains or to the total or global scores. Also, the tool is not intended to reduce the FQOL to a single score, but rather to provide information about each of the nine domains and to facilitate the identification of needs at the individual family level, to contribute to the improvement of the services and supports the families receive [40].

The convergent validity, tested by the relationships between the domain scores and the global FQOL score, showed a strong association of this score with Leisure and a moderate one with the domains of Community and Health, like the results obtained in prior research on family caregivers of people with dementia [9]. In the face of care demands required by a person with ND, caregiver families often restrict their participation in enjoyable activities and have few opportunities to maintain social networks, which can affect family well-being [9, 51]. Values was the only domain that was not directly associated with the global FQOL score. In summary, the positive correlations between the different subscales and the global FQOL score may mean that, in FQOL, satisfaction is measured similarly by the perceptions of the eight domains.

Internal consistency of the FQOLS-ND subscales was found to be excellent. Internal consistency of the 20-item total FQOL scale was also excellent. Internal consistency results are similar to those found in other studies using the original version of the instrument in caring families of people with DD and dementia [9,31]. However, it should be noted that the internal consistency rates of this study are somewhat higher and especially more significant in the Health, Finances, and Services subscales. The higher Cronbach alpha values obtained in our study, despite including a lower number of ítems, are explained 
because all the items included in our scale correspond to the outcome dimension (attainment and satisfaction).

The practical implications of the results obtained concerning the levels of evaluation, intervention, and planning of support services are multiple. Thus, the FQOLS-ND allows us to evaluate the FQOL profile of caring families of people with ND, identifying their needs and priorities. More specifically, it provides an assessment of the integral needs of the caring family, which serve as a guide for the design of comprehensive intervention plans, offering the necessary supports for the family to perform their caring functions with less discomfort and better FQOL. Finally, the $F Q O L S-N D$ is a useful tool for planning, organization, and evaluation of quality social healthcare services for people with ND and their families living in rural areas of the cross-border Spain-Portugal area.

The Coronavirus disease (COVID-19) affected the data collection for this study. One of the challenges was to review the contents of the instrument to develop a shorter version of the scale and facilitate the collection of the respondents' data. The translated and adapted Spanish version of the FQOLS-Dementia for a population with ND is an overly long instrument, as the authors of the original instrument point out [9]. For this reason, as indicated in the data collection and procedure sections, we chose to include only the attainment and satisfaction dimensions for the nine domains of FQOL to analyze the properties of the instrument.

Therefore, this study has some limitations. We could not analyze the factorial structure at two levels, like the authors of the original scale. Specifically, we could not analyze the item-level factor structure of the domains, the domain subscale aggregated from six dimensions, because only items corresponding to the dimensions of attainment and satisfaction were included in this study. On the other hand, the model we present is a model of FQOL outcome measures because the explanatory measures (importance, opportunities, initiative, and stability) were not included.

Finally, beyond the psychometric properties, a scale and user manual will be developed for the Spanish version to illustrate the scores in an FQOL profile that will facilitate the interpretation of the scores.

\section{Conclusion}

This study has provided evidence of the validity and reliability of the FQOLS-ND to assess the QOL of caring families of people with an ND in the cross-border SpainPortugal area. The findings highlight the importance of family involvement in leisure activities and community integration to increase their QOL. This tool's usefulness for improving FQOL results is noteworthy, implementing evidence-based practices and guiding the planning of support services.

\section{Abbreviations}

RHM: Regional Management of Health; CyL: Castille and Leon; CFA: Confirmatory factor analysis; ML: Maximum Likelihood; CFI: Comparative Fit Index; AGFI: Adjusted Goodness-of-Fit Index; RMSEA: Root Mean Square Error of Approximation; SMC: Squared Multiple Correlations; $\lambda$ : Standardized factor loadings.

\section{Supplementary Information}

The online version contains supplementary material available at https://doi. org/10.1186/s12955-021-01809-6.

Additional file 1. Escala de Calidad de Vida Familiar: Enfermedades neurodegenerativas.

\section{Acknowledgements}

The authors would like to thank the families of people with NDs and the health and social services professionals who collaborated in the study.

\section{Authors' contributions}

$\mathrm{MB}$ participated in the conception, design, and discussion section of the study. BO and AA did the statistical analyses and manuscript drafting. IVM wrote the introduction and method of the manuscripts. EGO and MGV contributed to the transcultural validation into Spanish. MMD participated in data acquisition. All authors participated in reviewing the manuscript. All authors read and approved the final manuscript.

\section{Funding}

This study was funded by the Project "NEUROQUALYFAM, Neurodegenerative Diseases and Family Quality of Life", funded by the Fondo Europeo de Desarrollo Regional (FEDER) through the program INTERREG V-A España-Portugal (POCTEP) 2014-2020.

\section{Availability of data and materials}

Data sharing is available upon reasonable request. Kindly contact the corresponding author.

\section{Declarations}

Ethics approval and consent to participate

The study was approved by the Bioethics Committee of the University of Salamanca (Protocol No. 2019/238). All procedures comply with the principles of the 1964 Declaration of Helsinki and its amendments. Verbal consent was obtained from all participants prior to data collection.

\section{Consent for publication}

Not applicable.

\section{Competing interest}

The authors declare that they have no competing interests.

\section{Author details}

${ }^{1}$ Institute on Community Integration (INICO), Faculty of Psychology, University of Salamanca, Avda. de la Merced, 109-131, 37005 Salamanca, Spain. ${ }^{2}$ Teacher Training College of Zamora, University of Salamanca, Avda. Príncipe de Asturias s/n, 49029 Zamora, Spain. ${ }^{3}$ Regional Health Management (RHM) of Castille and Leon (Spain), Paseo de Zorrilla, 1, 47007 Valladolid, Spain.

Received: 5 March 2021 Accepted: 19 June 2021

Published online: 30 June 2021 


\section{References}

1. World Health Organization. Dementia. Worl Health Organization: A public health priority. Geneva; 2012.

2. Garcés M. Estudio sobre las enfermedades neurodegenerativas en España y su impacto económico y social. (Madrid UCd, Neuroalianza eds.). Madrid; 2017.

3. Nieto Masot A, Cárdenas Alonso G, Engelmo MÁ. Spatial analysis of the rural-urban structure of the Spanish municipalities. Int J Geoinf. 2020:9:213.

4. Alonso-Sardón M, Neuroqualyfam Group. Informe epidemiológico de las enfermedades neurodegenerativas en la zona rural transfronteriza de la provincia de Salamanca; 2021. Available from: https://neuroqualyfam. usal.es/wp-content/uploads/sites/51/2021/03/NEUROQUALYFAM Infor me_Epidemiologico.pdf. Accessed 2 March 2021.

5. Cooper C, Balamurali TBS, Livingston G. A systematic review of the prevalence and covariates of anxiety in caregivers of people with dementia. Int Psychogeriatr. 2007;19:175-95

6. Cuijpers P. Depressive disorders in caregivers of dementia patients: a systematic review. Aging Ment Health. 2005;9:325-30.

7. Feast A, Moniz-Cook E, Stoner C, Charlesworth G, Orrell M. A systematic review of the relationship between behavioral and psychological symptoms (BPSD) and caregiver well-being. Int Psychogeriatr. 2016:28:1761-74

8. Cheng S-T. Dementia caregiver burden: a research update and critical analysis. Curr Psychiatry Rep. 2017;19:64.

9. Samuel PS, DiZazzo-Miller R. Family quality of life: perspectives of family caregivers of people with dementia. Phys Occup Ther Geriatr. 2019;1:94-107.

10. Riedel BC, Ducharme JK, Geldmacher DS. Family composition and expressions of family-focused care needs at an academic memory disorders clinic. J Alzheimer's Dis. 2013;2013:436271.

11. Esandi N, Canga A. Atención centrada en la familia: un modelo para abordar los cuidados de la demencia en la comunidad [Family-centered care: a model for approaching dementia care in the community]. Aten Prim. 2016;48:265-9.

12. DiZazzo-Miller R, Pociask F, Samuel P. Understanding resource needs of persons with dementia and their caregivers. Mich Fam Rev. 2013;17:1-2.

13. Isaacs BJ, Brown I, Brown RI, Baum N, Myerscough T, Neikrug S, Roth $D$, Shearer J, Wang M. The international family quality of life project: goals and description of a survey tool. J Policy Pract Intellect Disabil. 2007:4:177-85.

14. Summers JA, Poston DJ, Turnbull AP, Marquis J, Hoffman L, Mannan H, Wang M. Conceptualizing and measuring family quality of life. J Intell Disabil Res. 2005:49:777-83.

15. Park J, Hoffman L, Marquis J, Turnbull AP, Poston D, Mannan H, Wang M, Nelson LL. Toward assessing family outcomes of service delivery: validation of a family quality of life survey. J Intell Disabil Res. 2003:47:367-84.

16. Poston D, Turnbull A, Park J, Mannan H, Marquis J, Wang M. Family quality of life: a qualitative inquiry. Ment Retard. 2003:41:313-28.

17. Giné C, Gràcia M, Vilaseca R, Salvador Beltran F, Balcells Balcells A, Dalmau Montalà M, Luisa Adam-Alcocer A, Teresa Pro M, Simó Pinatella D, Maria Mas Mestre J. Family quality of life for people with intellectual disabilities in Catalonia J Policy Pract Intellect Disabil. 2015:12:244-54.

18. Bertelli M, Bianco A, Rossi M, Scuticchio D, Brown I. Relationship between individual quality of life and family quality of life for people with intellectual disability living in Italy. J Intell Disabil Res. 2011;55:1136-50.

19. Rillotta F, Kirby N, Shearer J, Nettelbeck T. Family quality of life of Australian families with a member with an intellectual/developmental disability. J Intell Disabil Res. 2012;56:71-86.

20. Zuna N, Summers J, Turnbull A, Hu X, Xu S. Theorizing about familiy quality of life. Enhancing the quality of life of people with intellectual disabilities: From theory to practice. In: Kober R, editor. Enhancing the quality of life of people with intellectual disabilities. Dordrecht: Springer; 2010. p. $241-78$

21. Zuna NI, Brown I, Brown RI. Family quality of life in intellectual and developmental disabilities: a support-based framework. Int Public Health J. 2014;6:161-84.

22. Balcells-Balcells A, Giné C, Guàrdia-Olmos J, Summers JA. Family quality of life: adaptation to Spanish population of several family support questionnaires. J Intell Disabil Res. 2011;55:1151-63.
23. Verdugo MA, Córdoba L, Gómez J. Spanish adaptation and validation of the Family Quality of Life Survey. J Intell Disabil Res. 2005;49:794-8.

24. Brown I, Brown R. Concepts for beginning study in family quality of life. In: Turnbull A, Brown I, Turnbull R, editors. Families and people with mental retardation and quality of life: international perspectives. American Association on Mental Retardation: Washington; 2004. p. 25-49.

25. Ducharme JK, Geldmacher DS. Family quality of life in dementia: qualitative approach to family-identified care priorities. Qual Life Res. 2011;20:1331-5.

26. Keady J, Braudy HP. Editorial: Family matters. Dementia. 2009;8:5-8.

27. Ducharme F, Kergoat MJ, Antoine P, Pasquer F, Coulombe R. Caring for individuals with early-onset dementia and their family caregivers: the perspective of health care professionals. Adv Alzheimer's Dis. 2014;3:33-43.

28. Hu X, Summers JA, Turnbull A, Zuna N. The quantitative measurement of family quality of life: a review of available instruments. J Intell Disabil Res. 2011:55:1098-114.

29. Samuel PS, Rillotta F, Brown I. The development of family quality of life concepts and measures. J Intell Disabil Res. 2012;56:1-16.

30. Brown I, Brown RI, Baum NT, Isaacs BJ, Myerscough T, Neikrug S, Roth D, Shearer J, Wang M. Family Quality of Life Survey: main caregivers of people with intellectual disabilities. Toronto: Surrey Place Centre; 2006.

31. Isaacs B, Wang M, Samuel P, Ajuwon P, Baum N, Edwards M, Rillotta F. Testing the factor structure of the Family Quality of Life Survey-2006. J Intell Disabil Res. 2012;56:17-29.

32. Perry A, Isaacs B. Validity of the Family Quality of Life Survey-2006. J Appl Res Intell Disabil. 2015;28:584-8.

33. Samuel PS, Pociask FD, DiZazzo-Miller R, Carrellas A, LeRoy BW. Concurrent validity of the international Family Quality of Life Survey. Occup Ther Health Care. 2016;30:187-201.

34. DiZazzo-Miller R, Samuel PS. Family Quality of Life Survey: main caregivers of person with dementia. Detroit:Wayne State University; 2011.

35. Arkin H, Colton RR. Tables for statisticians. 2nd ed. New York: Barnes \& Noble; 1963.

36. Muñiz J, Elosua P, Hambleton RK. Directrices para la traducción y adaptación de los tests: Segunda edición [International Test Commission Guidelines for test translation and adaptation: Second edition]. Psicothema. 2013;25:151-7.

37. Beaton D, Bombardier C, Guillemin F, Ferraz M. Guidelines for the process of cross-cultural adaptation of self-report measures. Spine. 2000:35:3186-91.

38. McHorney CA, Tarlov AR. Individual-patient monitoring in clinical practice: Are available health status surveys adequate? Qual Life Res. 1995:4:293-307.

39. Cohen J. Stadistical power analysis for the behavioural sciences. 2nd ed. Hillsdale: Erlbaum; 1988.

40. Samuel PS, Tarraf W, Marsack C. Family Quality of Life Survey (FQOLS2006): evaluation of internal consistency, construct, and criterion validity for socioeconomically disadvantaged families. Phys Occup Ther Pediatr. 2018;38:46-63.

41. Byrne BM. Structural equation modeling with AMOS: basic concepts, applications and programming. Mahwah: Lawrence Erlbaum Associates; 2001.

42. Terwee $C B$, Bot SDM, de Boer MR, van der Windt DAWM, Knol DL, Dekker J, Bouter LM, de Vet HCW. Quality criteria were proposed for measurement properties of health status questionnaires. J Clin Epidem. 2007;60:34-42.

43. Ley 39/2006, Promoción de la autonomía personal y atención a las personas en situación de dependencia [Promotion of personal autonomy and care of people in a dependency situation]. BOE, 299 of 15/12/2006.

44. Losada Baltar A, Márquez González M, Vara García C, Gallego Alberto L, Romero Moreno R, Olazarán RJ. Impacto psicológico de las demencias en las familias: propuesta de un modelo integrador. Clínica Contemporánea. 2017:8:1-27.

45. Rogero García J, Instituto de Mayores y Servicios Sociales (España). Los tiempos del cuidado: el impacto de la dependencia de los mayores en la vida cotidiana de sus cuidadores. Madrid: Instituto de Mayores y Servicios Sociales; 2010.

46. Bauer M, Fetherstonhaugh D, Blackberry I, Farmer J, Wilding C. Identifying support needs to improve rural dementia services for people with dementia and their carers: a consultation study in Victoria. Australia Aust J Rural Health. 2019:27:22-7. 
47. Brown Rl, MacAdam-Crisp J, Wang M, laroci G. Family Quality of Life when there is a child with a developmental disability. J Policy Pract Intell Disabil. 2006;3:238-45.

48. Farina E, Villanelli F, Baglio F. Intervention program mediated by recreational activities and socialization in groups for PWA with Alzheimer's disease. In: Söderback I, editor. International handbook of occupational therapy interventions. 2nd ed. Cham: Springer International Publishing; 2015. p. 769-85.

49. Alwin J, Oberg B, Krevers B. Support/services among family caregivers of persons with dementia-perceived importance and services received. Int $J$ Geriatr Psychiatry. 2010;25:240-8.

50. McCabe M, You E, Tatangelo G. Hearing their voice: a systematic review of dementia family caregivers' needs. Gerontologist. 2016;56:e70-88.
51. Daley S, Murray J, Farina N, Page TE, Brown A, Basset T, Livingston G, Bowling A, Knapp M, Banerjee S. Understanding the quality of life of family carers of people with dementia: development of a new conceptual framework. Int J Geriatr Psychiatry. 2018;34:79-86.

52. Losada A, Pérez-Peñaranda A, Rodríguez-Sánchez E, Gómez-Marcos MA, Ballesteros-Ríos C, Ramos-Carrera IR, Campo-de la Torre MA, García-Ortiz L. Leisure and distress in caregivers for elderly patients. Arch Gerontol Geriatr. 2010;50:347-350.

\section{Publisher's Note}

Springer Nature remains neutral with regard to jurisdictional claims in published maps and institutional affiliations.
Ready to submit your research? Choose BMC and benefit from:

- fast, convenient online submission

- thorough peer review by experienced researchers in your field

- rapid publication on acceptance

- support for research data, including large and complex data types

- gold Open Access which fosters wider collaboration and increased citations

- maximum visibility for your research: over $100 \mathrm{M}$ website views per year

At BMC, research is always in progress.

Learn more biomedcentral.com/submissions 